\title{
Current Dietary Pattern In Central Italy
}

\author{
Elena Matteucci* and Ottavio Giampietro
}

Department of Internal Medicine, University of Pisa, Italy

\begin{abstract}
Nutrition is considered to be one of the key components in the development of most chronic degenerative diseases so that medical nutrition therapy has become important in their primary prevention. Food-based dietary guidelines provide the following values: the Lowest Threshold Intake (LTI), the Average Requirement (AR) and the Population Reference Intake (PRI) or Recommended Dietary Allowance (RDA). RDA indicates the quantity of a nutrient that must be present in the food supply if the dietary requirements of most of the population are to be met. Contrary to the established optimistic belief about Mediterranean diet, we have repeatedly documented widespread unhealthy dietary behaviours in adult subjects living in Pisa. The distribution of energy sources was incorrect and fibre consumption did not match general guidelines. Moreover, mild to moderate combined element (calcium) and vitamin (vitamin B1, folates, vitamin D, and vitamin E) deficient intakes were observed. The finding of essential nutrient deficiencies in otherwise over-nourished adults prompted us to reconsider the variety and abundance of foods required to guarantee the reference requirements for those substances and which are the historical, environmental, and contingent factors able to prevent the adequacy of food supplies in meeting physiological needs.
\end{abstract}

Keywords: Nutrition, chronic diseases, fibres, calcium, folates, vitamin B1, vitamin D, vitamin E.

\section{NUTRIENT REQUIREMENTS IN HUMAN NUTRI- TION}

The acceptable approaches to setting dietary guidelines include the epidemiological approach and the food consumption approach; these two may be used together.

The Food and Nutrition Board of the U.S. National Academy of Sciences established and then updated a set of recommendations of a standard daily allowance for each type of nutrient since 1941. In 1981, in consideration of the recurring confusion in literature and the multiplicity of terminology used, a joint FAO/WHO/UNU Expert Consultation on Energy and Protein Requirements proposed a consensus document entitled Minimum physiological requirements and recommended dietary allowances [1]. The concept of risk was applied to the recommended intake, set at the average requirement +2 standard deviations (assuming a Gaussian distribution), so that the probability of the recommended intake being inadequate was only 0.025 . The Recommended dietary allowance (RDA) indicates the quantity of a nutrient that must be present in the food supply if the needs of most (97.5\%) of the populations are to be met. In 1993 the Scientific Committee for Food (SCF) provided values for several indices of nutritional adequacy [2]. The SCF suggested the Population Reference Intake (PRI) in the place of RDA and set a new index, the Lowest Threshold Intake (LTI) that is the intake below which almost all individuals will be unlikely to maintain metabolic integrity.

In 1997, the Food and Nutrition Board of the National Academy of Sciences proposed a set of values as standards for nutrient intakes for healthy persons. The Dietary References Intakes (DRIs) reference values included: the Estimated Average Requirement (EAR), the RDA, the Adequate

*Address correspondence to this author at the Dipartimento di Medicina Interna, Via Roma 67, 56126 Pisa, Italy; Tel: 0039050 993246; Fax: 0039 050 553414; E-mail: ematteuc@int.med.unipi.it
Intake (AI), and the Tolerable Upper Intake Level (UL) [3]. The EAR is defined as the nutrient intake value estimated to meet the requirement of $50 \%$ of the healthy individuals. The AI is set for those nutrients for which scientific data are insufficient to establish an EAR and a RDA. The UL is the maximum level of total chronic daily intake of a nutrient judged to be unlikely to pose a risk of adverse health effects to human. Acceptable Macronutrient Distribution Ranges (AMDR) have successively been established: the range of intakes of an energy source that is associated with a reduced risk of chronic disease yet can provide adequate amounts of essential nutrients. The ULs of micronutrients have been also reviewed by the SCF [4]. A comparison between the recent DRI reports and the previous RDAs is available at http//www.mypyramid.gov; differences in RDA set by medical authorities in the UK, the European Union and the USA can be found at http://www.nassdb.org.uk/f2/Vitamins Minerals.htm. Since the recommended intake levels have been generally established on the basis of the reference intakes in adult men and women, they differ from U.S.A. to Europe (Table 1). A singular aspect of the problem is that, as Walter Willett said, we never had a high level of proof to set current nutritional recommendations but the prevention of the index disease [5]. On the one hand, the classic vitamin deficiency syndromes (such as beriberi, pellagra, scurvy, rickets, etc.), that are short-latency diseases, have become uncommon in Western societies, although some subgroups remains at risk (elderly subjects, hospitalised patients, and alcohol-dependent individuals). On the other hand, the scientific community renewed the interest in the role of low nutrient intake in nonindex, long-latency, multifactorial disorders such as cancer, cardiovascular disease, central nervous system degeneration [6]. For example, inadequate calcium intake has been suggested to produce the calcium paradox disease that could be associated with obesity and hypertension. Folate deficiency is characterised by macrocytic anemia and fetal neural tube defects, but it could also contribute to coronary artery disease (together with vitamins B6 and 
Table 1. The Dietary References Intakes (DRI) and Tolerable Upper Intake Levels (UL), reported by gender and life stage group, are the most recent set of dietary recommendations established by the Food and Nutrition Board of the Institute of Medicine (1997-2001). The EU Scientific Committee established the Population Reference Intakes for Food

\begin{tabular}{|c|c|c|c|c|c|}
\hline \multirow[t]{2}{*}{ Life stage group } & \multicolumn{5}{|c|}{ MICRONUTRIENT } \\
\hline & Calcium (mg) & Vitamin B1 (mg) & Folates $(\mu \mathrm{g})$ & Vitamin $D(\mu \mathrm{g})$ & Vitamin E (mg) \\
\hline Females $19-30$ y & 1000 & 1.1 & 400 & 5 & 15 \\
\hline Females $>70 y$ & 1200 & 1.1 & 400 & 10 & 15 \\
\hline Males $19-30$ y & 1000 & 1.2 & 400 & 5 & 15 \\
\hline Males $31-50$ y & 1000 & 1.2 & 400 & 5 & 15 \\
\hline $19-70$ y & 1000 & ND & 1000 & 50 & 1000 \\
\hline \multirow[t]{2}{*}{$>70 y$} & 1200 & ND & 1000 & 50 & 1000 \\
\hline & \multicolumn{5}{|c|}{ POPULATION REFERENCE INTAKES } \\
\hline Males +18 y & $800(2500)$ & $1.1(50)$ & $200(1000)$ & $5(50)$ & $10(1000)$ \\
\hline Females +18 y & $800(2500)$ & $0.9(50)$ & $200(1000)$ & $5(50)$ & $10(1000)$ \\
\hline
\end{tabular}

B12) as well as colon and breast cancer. Furthermore, setting requirements by estimating the amount of vitamin necessary to reverse symptoms of vitamin deficit markedly differs from establishing the amount of vitamin necessary to reduce the risk of chronic diseases. The recommended vitamin D requirements prevent rickets and osteomalacia, but higher serum $25(\mathrm{OH}) \mathrm{D}$ concentrations than usual "reference" ranges could be required for the autocrine function of vitamin D [7]. Higher serum concentrations of vitamin E were associated with significant reductions in total and cause-specific mortality [8].

\section{TIME TRENDS OF THE DIETS IN EUROPE (WITH PARTICULAR REFERENCE TO ITALY)}

The Data Food Networking (DAFNE) initiative is a joint effort of European countries to compare the food habits of their populations and monitor overtime trends in food availability, through the creation of a regularly updated food databank (http://www.nut.uoa.gr/english/). The aim is the development of a nutrition monitoring tool that could assist the formulation, implementation and evaluation of nutritional policies across Europe. The DAFNE databank is based on information collected in the context of household budget surveys (HBS) that are periodically conducted by the National Statistical Offices of most European countries in country-representative samples of households. By recording data on the values and quantities of household food purchases, HBS can adequately depict the dietary patterns prevailing in representative population samples. The concurrent recording of demographic and socioeconomic characteristics of the household members allows the evaluation of the effects of these characteristics on dietary choices. The DAFNE databank allows inter-country comparisons of daily individual food availability, comparisons of the eating behaviour of various population segments, and the identification of dietary patterns.

In the Mediterranean and Asian countries, traditional eating patterns have been considered healthful because associated with low rates of chronic diet-related diseases. However, traditional diets vary substantially from place to place and, in developed nations, are rapidly changing.

The Scientific and Technological Options Assessment (STOA) report on Nutrition in Europe summarised the following components of the historical Mediterranean diet [9]:

- abundance of food from plant sources,

- $\quad$ variety of minimally processed, seasonally fresh and locally grown foods,

- $\quad$ olive oil as principal fat,

- total fat ranging from less than $25 \%$ to over $35 \%$ (around 28\% in Italy) with the monounsaturated-tosaturated fats ratio usually $\geq 2$,

- daily consumption of low to moderate amounts of cheese and yoghurt,

- weekly consumption of low to moderate amounts of fish and poultry and few eggs, 
- $\quad$ fresh fruit as typical dessert,

- $\quad$ red meat few times per month,

- $\quad$ moderate consumption of wine.

By re-analysing the data from EURATOM survey on diets in Europe, profound regional differences emerged in Italy. In Southern Italy, cereals contributed to $60 \%$ of total dietary energy; sugar and confectionery provided less than $2 \%$ of total energy. Fruiting vegetables and green leafy vegetables dominated; milk, dairy products and meat were consumed much less than anywhere else; $28 \%$ of energy derived from lipids (only $7 \%$ saturated fatty acids). On the contrary, in Northern Italy, total dietary lipid energy content was $34 \%$ (14\% saturated fatty acids). Sugar and confectionery amounted to 7-14\%; potatoes, other roots and tuber comprised the bulk of vegetables. After World War II, major changes occurred: the amount consumed of cereal, cereal products, potatoes and other starchy roots have decreased, whereas increased the consumption of meat, milk and milk products.

The STOA document on European Policy of Food Safety [10] evidenced that the general increase in the quantity and variety of food available has been accompanied by the emergence of diet-related diseases as an important cause of death. Degenerative conditions such as cardiovascular disease, cancer, diabetes, obesity, osteoporosis and hypertension were prevalent in the European society. Cardiovascular disease was the main cause of death in the European Union (42\% of all deaths before the age of 74 years). Cancer accounted for $29 \%$ of all deaths in men and $22 \%$ of female deaths. The prevalence of obesity was rising in all age groups.

Data from the food balance sheets collected yearly by FAO showed that the European eating patterns have been subject to various changes. There was a constant increase in the meat supply from $185 \mathrm{~g} /$ person/day in 1970 to 236 g/person/day in the late 1990s. Cereal availability has been generally static. Since 1978 fruit supply has continuously increased, reflecting consumers' documented preference for increasing their fruit rather than vegetable intake. The availability of vegetable oils has generally always been higher than that of animal fat. In the 1970s, the supply of both vegetable oils and animal fats was estimated at approximately 37 g/person/day. However, since 1978, a remarkable increase in the availability of vegetable oils has occurred, which has not been followed by a similar trend in the availability of animal fat. The availability of fruits and vegetables is higher in the south of Europe $(617 \mathrm{~g} /$ person/day in Greece and 488 in Spain, while 276 in Norway and only 233 in the Republic of Ireland). Northern populations more often include processed fruit and vegetable products in their daily diet. Ninety six percent $(96 \%)$ of fruits and vegetables are consumed fresh in Greece, compared with an estimated $66 \%$ in the United Kingdom.

Total added lipid availability lies between 72 $\mathrm{g} /$ person/day in Greece and $33 \mathrm{~g} /$ person/day in the UK. In Greece and Spain, however, vegetable oils (particularly olive oil) provide the totality of the availability. Vegetable fat is the prevailing lipid in Central and Northern Europe, whereas in Eastern European countries, butter and animal fat are more prominent.

\section{CURRENT DIETARY PATTERN IN CENTRAL IT-} ALY

Interesting findings emerged from a first study we conducted in type 1 diabetes families and healthy control subjects [11]. We obtained a detailed assessment of nutrient intake levels and lifestyle using standardised European Prospective Investigation of Cancer and Nutrition (EPIC) questionnaires adapted for use in the Italian population. Anthropometric indices and nutritional biomarkers (such as plasma levels of albumin, iron, lipids, homocysteine, vitamin $\mathrm{B}_{9}$ and vitamin $B_{12}$ as well as urinary outputs of nitrogen, sodium and potassium) were also evaluated.

Emerging health issues were:

- $45 \%$ of controls were overweight.

- The distribution of energy sources was incorrect. The proportion of caloric intake derived from total fat and cholesterol did not match general guidelines. Most controls (presumed to be consuming a free diet) ate up to $50 \%$ more protein than recommended as RDAs/AIs. Total dietary fibre consumption was adequate $(25 \mathrm{~g} / \mathrm{d})$ in only $27 \%$ of all the participants.

- $\quad$ Estimated daily intakes of water-soluble vitamin $\mathrm{B}_{9}$ (or total folates) and fat-soluble vitamin D (sum of ergocalcipherol and cholecalcipherol) and vitamin $\mathrm{E}$ (sum of all tocopherols and tocotrienols) were deficient in comparison with RDAs and AIs $(400 \mu \mathrm{g}, 5$ to $10 \mu \mathrm{g}$, and $15 \mathrm{mg}$, respectively).

Moreover, estimated intakes of sodium $(2.8 \pm 1.1 \mathrm{~g})$ were significantly underreported in comparison with values derived from urinary measurements $(3.9 \pm 1.7 \mathrm{~g}, \mathrm{p}<0.001)$. The latter values consistently were higher than presently suggested AI of 1.3-1.5 g sodium per day (www.iom.edu).

Thus, current diet of residents from Pisa province did not provide appropriate amounts of macro and micronutrients. EPIC data in the Italian EPIC cohorts [12], the Data Food Networking Reports [13], and evidence from a primary school health program carried out in Pisa [14] confirmed that Italian eating habits are undergoing marked changes with a tendency to less healthy eating. Considered that RDA values probably rely on outdated concepts of deficiency diseases and the special issue needs a reappraisal of current knowledge as to the optimal dietary intake for minimising degenerative diseases [15], the observed diet patterns may be seriously inadequate for health. Indeed, the approach of setting requirements by estimating the amount of a nutrient necessary to reverse symptoms of deficiency is different from the approach of establishing the amount necessary to reduce the risk of chronic diseases.

The upper-mentioned findings were confirmed by a successive study designed to investigate and improve the nutrition and the lifestyle of type 2 diabetes patients with high cardiovascular risk [16]. In that study, dietary assessment was performed by a detailed dietary recall. Weights of food were estimated using a standard reference guide and analysed by a trained operator using Microdiet software (Salford University). Data from 193 24-hour dietary recalls evidenced that mean dietary energy intake was $1664 \pm 441 \mathrm{kcal} /$ day, the percentage of energy from protein was $18 \pm 4 \%$, carbohydrate $49 \pm 7 \%$, total lipid $31 \pm 8 \%$, P/S ratio was $0.89 \pm 0.54$. Daily 
intake of cholesterol was > $200 \mathrm{mg} / \mathrm{day}$ in 69 of 193 24-hour dietary recalls; daily intake of sodium was above 2300 $\mathrm{mg} /$ day in 132 recalls.

The following daily intakes were below RDAs/AIs: fibre $22 \pm 6 \mathrm{~g} / \mathrm{day}(<21 \mathrm{~g} / \mathrm{d}$ in 136 of 19324 -hour dietary recalls $)$; calcium $1100 \pm 500 \mathrm{mg} /$ day $(<1200 \mathrm{mg} /$ day in $185 / 193)$; vitamin B1 $1.1 \pm 0.3 \mathrm{mg} /$ day $(<1.1 \mathrm{mg} /$ day in 154$)$; vitamin B9 or total folates $282 \pm 73 \mu \mathrm{g} / \mathrm{day}(<400 \mu \mathrm{g} / \mathrm{day}$ in 164$)$; vita$\min \mathrm{D} 3.2 \pm 1.4 \mu \mathrm{g} /$ day $(<10 \mu \mathrm{g} / \mathrm{day}$ in 183$)$; vitamin $\mathrm{E}$ $8.3 \pm 2.4 \mathrm{mg} /$ day $(<15 \mathrm{mg} /$ day in 188$)$. Thus, were inadequate the intakes of several vitamins and calcium in aged diabetics.

\section{AIM}

The finding of essential nutrient deficiencies in otherwise over-nourished adults prompted us to reconsider the variety and abundance of foods required to guarantee the reference requirements for those substances and which are the historical, environmental, and contingent factors able to prevent the adequacy of food supplies in meeting physiological needs.

We will consider separately the RDAs for men and women of fibre and micronutrients (calcium, vitamin B1, total folates, vitamin D, vitamin E) whose estimated daily intake resulted inadequate in our previous investigation [11] and the dietary sources principally contributing the suggested amounts of those naturally occurring nutrients.

\section{DIETARY FIBRE}

Dietary fibres (cellulose, hemicellulose, pectin, guar, psyllium, beta-glucan, Klason lignin and digestion-resistant starch) play an essential role in the physiology of the gastrointestinal tract. Total dietary fibre consumption and fibre supplementation could contribute to the prevention of hypertension [17], diabetes [18], and colorectal cancer [19]. Dietary fibres include water-soluble and insoluble fibres that are present in plant foods and in fibre preparations. Viscous and gel-forming properties of soluble dietary fibres were found to beneficially influence blood lipids and postprandial gly- caemia, although, in prospective studies, reduced diabetes risk was significantly associated with insoluble cereal fibres [20]. The American Heart Association recommends at least the amount of $25 \mathrm{~g} /$ day, whereas the $73 \%$ of our interviewed subjects reported a daily fibre intake less than $25 \mathrm{~g}$ [11]. The food frequency EPIC questionnaire calculates energy and nutrient intakes from dietary assessment by using data from the Italian food code [21]. Daily amount (vq, g/day) and daily frequency of consumption (vf) of specific food items are also provided. The sources of fibre intake in our centre were (in order of decreasing importance) fruits, bread, pasta, legumes, and cakes. The medians of $\mathrm{vq}$ and $\mathrm{vf}$ for each food group in the observed standard Italian diet are summarised in Table 2. As shown in the Table, unfortunately, current Italian dietary habits do not include the frequent consumption of wholemeal pasta or bread, raw vegetables or salad.

\section{DIETARY CALCIUM AND VITAMIN D}

The requirement for calcium remains elevated even in adult subjects because: 1) bone serves as nutrient reserve for calcium beyond its structural role, 2) intestinal calcium absorption from food sources is inefficient, and 3) the ability to adapt to inadequate calcium intakes decreases with age. Dietary calcium deficiency is considered to produce osteoporosis among adults; however, vitamin D insufficiency and low dietary calcium intake should combine to induce rickets [22]. In our study, 51 of the 204 participants (25\%) had an estimated dietary calcium intake less than $800 \mathrm{mg} / \mathrm{day}, 100$ (49\%) less than $1000 \mathrm{mg} /$ day. The principal source of dietary calcium was cheese consumption, since daily milk intake did not reach the recommended amount of $200-250 \mathrm{ml}$ and yoghurt consumption was infrequent (Table $\mathbf{3}$ ).

The hypovitaminosis D osteopathy evolves through successive degrees: calcium malabsorption without histologic abnormalities, calcium malabsorption and osteoporosis, rickets or osteomalacia. However, evidence indicates malfunctioning and morbidity, correctable with vitamin $\mathrm{D}$, in persons who do not have the index disease [7]. When sun exposure is

Table 2. The medians of daily amount (vq, g/day) and daily frequency of consumption (vf) of food items mainly contributing to fibre intake. The content in fibre in the left column refers to the food indicated within brackets

\begin{tabular}{|c|c|c|c|}
\hline Food & vq (g/day) & vf (frequency) & Fibre (g/100 g) \\
\hline \hline Fruit (apple) & 208 & 3.7 & 2.0 \\
\hline Bread & 155 & 0.3 & 5.8 \\
\hline Crispbread & 3.0 & 0.9 & 2.6 \\
\hline Pasta & 75 & 0.2 & 10.6 \\
\hline Legumes (beans) & 15 & 0.3 & 2.5 \\
\hline Cakes (brioche) & 28 & 0.3 & 1.6 \\
\hline Potatoes & 23 & 0.6 & 1.5 \\
\hline Leafy vegetables, raw (lettuce) & 14 & 0.2 & 1.9 \\
\hline Leafy vegetables, cooked (spinach) & 10 & 0.2 & 2.6 \\
\hline Fruiting vegetables (eggplant) & 20 & 0.4 & 1.0 \\
\hline Tomatoes, raw & 60 & & \\
\hline
\end{tabular}


limited, a dietary intake of vitamin D is required to maintain the circulating levels of 25 hydroxyvitamin $\mathrm{D}_{3}$, the precursor of the active form of vitamin D synthesised in the renal proximal tubule. Extra-renal tissues are also able to synthesise 1,25-dihydroxyvitamin $\mathrm{D}$ that critically regulate key autocrine function. Whereas circulating 25 hydroxyvitamin $\mathrm{D}_{3}$ levels of 20-29 nmol/L prevent rickets, levels of $75-80$ $\mathrm{nmol} / \mathrm{L}$ should be required to support both endocrine and autocrine functions [23]. In the winter, a mean requirement of at least $12.5 \mu \mathrm{g}$ has been calculated to prevent the increase in bone turnover associated with vitamin D drop. In many countries, without food fortification or supplement use, vitamin D intake is usually inadequate. All participants in our study had a daily vitamin D intake below $10 \mu \mathrm{g}$ and 184 (90\%) had an intake below $5 \mu \mathrm{g} / \mathrm{day}$. As shown in Table 3, low daily fish and milk (not fortified) consumption in Pisa could not provide the necessary vitamin $\mathrm{D}$ intake requirement.

\section{VITAMIN B1}

The index disease for vitamin B1 is beriberi. One form, called dry beriberi, causes nerve and muscle abnormalities, whereas wet beriberi causes heart abnormalities till to heart failure. Thiamine inadequate intake may be associated with alcohol abuse where brain abnormalities primarily occur.

B vitamins deficiency has been supposed to be involved in the pathogenesis of age-related neurodegenerative disorders; they affects cognitive function, movement disorders, brain neurotransmitters and histopathology in animal and in vitro models. Thiamine-depleted diets induce damage in rats' brains and impair their performance in neurocognitive tests (http://www.ncbi.nih.gov/books/bv.fcgi?rid=hstat1b.chapter. 42480).

A previous assessment of vitamins B1 and B2 status in an adult Spanish population (by both 48 hour recall and biochemical analyses) found that intakes were below two-thirds of the recommended dietary allowance for vitamin $\mathrm{B} 1$ in $7.8 \%$ of the men and $4.5 \%$ of the women. Age, educational level, alcohol use and smoking were also associated with differences in the intake of this nutrient. Biochemical analyses confirmed a vitamin B1 deficient status in $6.4 \%$ of the population [24]. Of the 204 participants in our study, 144 (71\%) had a daily vitamin B1 intake below $1.2 \mathrm{mg}, 80$ (39\%) below $1.0 \mathrm{mg}$, and $27(13 \%)$ below $0.8 \mathrm{mg}$ (Table 4). Vitamin B1 intake decreased with age (Rho $-0.20, \mathrm{p}<0.01$ ) (Fig. 1). No significant relationship emerged between vitamin B1 intake and usual alcohol consumption, smoking, or educational level. Since the risk of dietary inadequacy faced by an individual increases as his intake moves from the mean of a nutrient intake distribution toward the lower part, those individuals whose vitamin B1 intake was below $0.8 \mathrm{mg}$ could be considered at risk for long-latency disorders.

\section{TOTAL FOLATES}

Folate (vitamin B9) is necessary for purine and pyrimidine synthesis, erythropoiesis, and methionine regeneration. Its deficiency is characterised by macrocytic anaemia. Folate is required for embryogenesis and folate supplementation prevents neural tube defects. Moreover, low folate intake or low blood folate levels have been associated with an increased risk of coronary heart disease, stroke, colon and breast cancer. Firstly, folate, along with vitamin B6 and vitamin B12, critically determines plasma homocysteine levels. Secondly, folate is involved in DNA synthesis by regulating methionine availability [6]. Folate DRI is $400 \mu \mathrm{g} / \mathrm{day}$, whereas folate PRI is $200 \mu \mathrm{g} / \mathrm{day}$. However, folate at 800 $\mu \mathrm{g} /$ day was necessary to minimise homocysteine levels. In our study sample, 181 of 204 subjects (89\%) had an estimated dietary intake of folate $<400 \mu \mathrm{g} / \mathrm{day}$, and $24(12 \%)$ subjects had an intake $<200 \mu \mathrm{g} / \mathrm{day}$.

Research on the relationship between diet and cancer points to the protective effect of vegetable consumption rather than fruit intake. Life expectancy for Italian men consuming more than $60 \mathrm{~g} /$ day vegetables was greater than for those consuming less than $20 \mathrm{~g} /$ day [25]. Data from the Third National Health and Nutrition Examination Survey (based on 24-hour recalls and serum micronutrient levels) were used to investigate the relationship between salad and raw vegetables consumption and nutritional status. Salad

Table 3. The medians of daily amount (vq, g/day) and daily frequency of consumption (vf) of food items mainly contributing to calcium and vitamin $D$ intake. The content in micronutrient in the left column refers to the food indicated within brackets

\begin{tabular}{|c|c|c|c|}
\hline Food & vq (g/day) & vf (frequency) & Calcium (g/100 g) \\
\hline \hline Milk & 160 & 1.0 & 1.2 \\
\hline Cheese (parmigiano) & 43 & 0.1 & 1340 \\
\hline Yoghurt & 8 & vf (frequency) & Vitamin D ( $\mathbf{\mu g} / \mathbf{1 0 0} \mathbf{g})$ \\
\hline Food & $\mathbf{v q}$ (g/day) & 0.2 & 11.0 \\
\hline \hline Fish (swordfish) & 29 & 0.3 & 1.75 \\
\hline Egg, chicken, whole & 14 & 0.3 & 2.61 \\
\hline Cakes (sponge cake) & 28 & 0.1 & 1.30 \\
\hline Veal & 8 & 1.0 & 0.03 \\
\hline
\end{tabular}


Table 4. The medians of daily amount (vq, g/day) and daily frequency of consumption (vf) of food items contributing to the intake of thiamin (vitamin B1), folates (vitamin B9), and vitamin E. The content in micronutrient in the left column refers to the food indicated within brackets

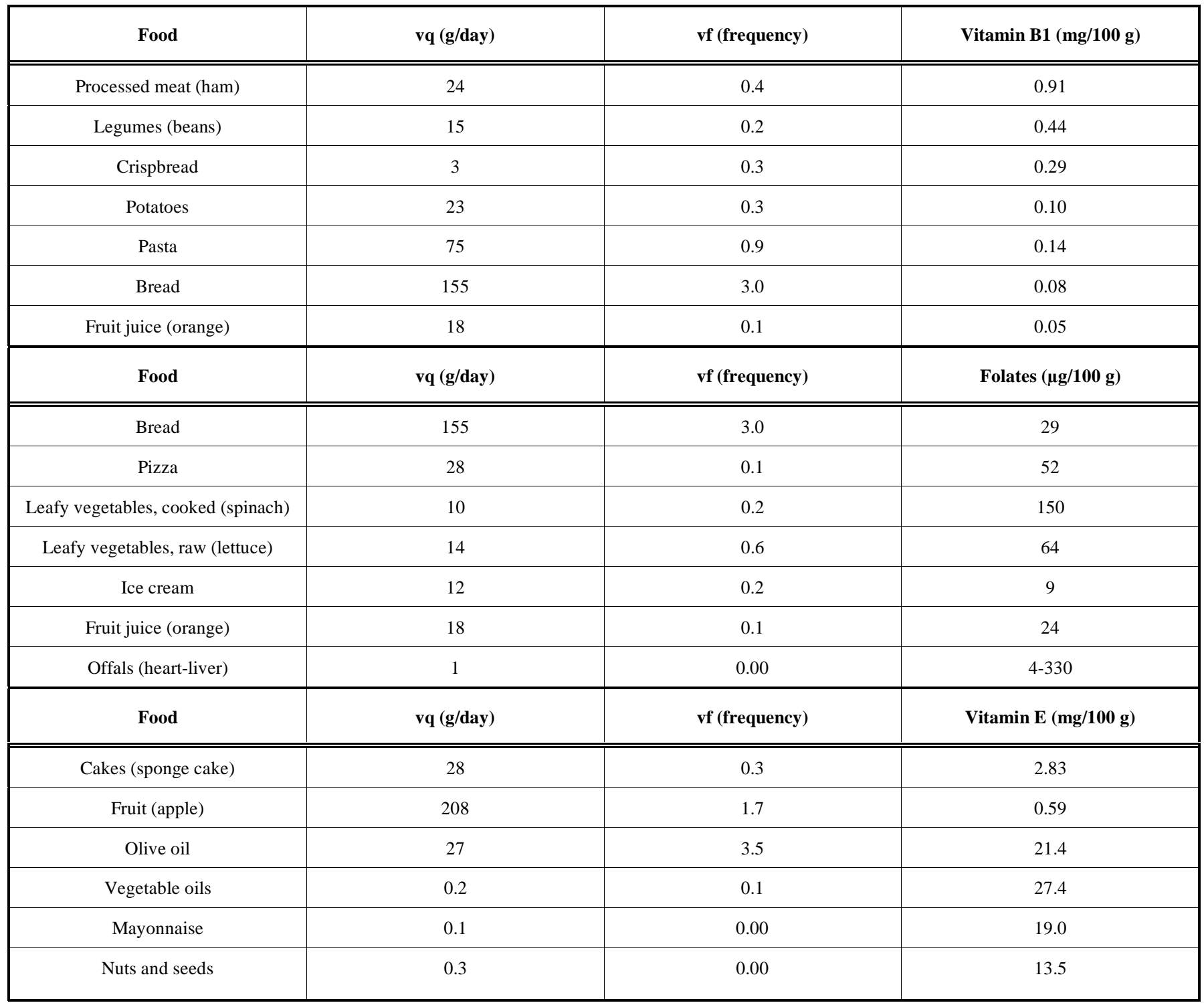

consumers had more favourable intakes of folic acid, vitamins $\mathrm{C}$ and $\mathrm{E}$, and carotenoids. Salad, salad dressing, and raw vegetable consumption were associated with a higher likelihood to meet the recommended nutrient intakes based on the DRIs and to have above average serum indicators of nutrient adequacy [26]. The median portion sizes and frequencies of consumption of vegetables in our sample were very small and did not change significantly with age, gender, cigarette smoking, or educational level.

\section{VITAMIN E}

Vitamin E includes a family of tocopherol and tocotrienol isomers; its deficiency has been associated with infertility and delayed-onset ataxia in animals, and with neuronal dysfunction in human subjects [27]. The prevention of hydrogen peroxide-induced haemolysis, assessed in vitro, is the surrogate marker of early vitamin E deficiency. Erythrocyte haemolysis was greater with serum vitamin E concen- trations below $11 \mu \mathrm{mol} / \mathrm{L}$ so that concentrations of $12-14$ $\mu \mathrm{mol} / \mathrm{L}$ were considered adequate. However, the amount of vitamin E necessary to reduce the risk of chronic diseases associated with oxidative stress remains to be established [28]. The Alpha-Toccopherol, Beta-Carotene Cancer Prevention Study observed that men in the highest quintile of baseline serum concentrations of alpha-tocopherol $(30 \mu \mathrm{mol} / \mathrm{L})$ had significantly lower risks of total and cause-specific mortality (including lung and prostate cancer, cardiovascular disease, and respiratory disease) than did men in the lowest quintile $(21 \mu \mathrm{mol} / \mathrm{L})$. How much alpha-tocopherol has to be consumed to achieve that serum concentration can be estimated using a dose-response design. In normolipidemic subjects, serum alpha-tocophrol can be raised from $20 \mu \mathrm{mol} / \mathrm{L}$ to $33 \mu \mathrm{mol} / \mathrm{L}$ by consuming $100 \mathrm{IU}$ vitamin E supplements. Vitamin E food sources are nuts, seeds, olive oil and other vegetable oils. Even though olive oil is a popular dressing in Italy, the vitamin $\mathrm{E}$ recommended dietary allowance of 15 $\mathrm{mg} /$ day was achieved only by 3 of 204 (1.5\%) participants in 
our study; 187 (92\%) had intakes below $12 \mathrm{mg} /$ day and 84 (41\%) below $7.5 \mathrm{mg} /$ day.

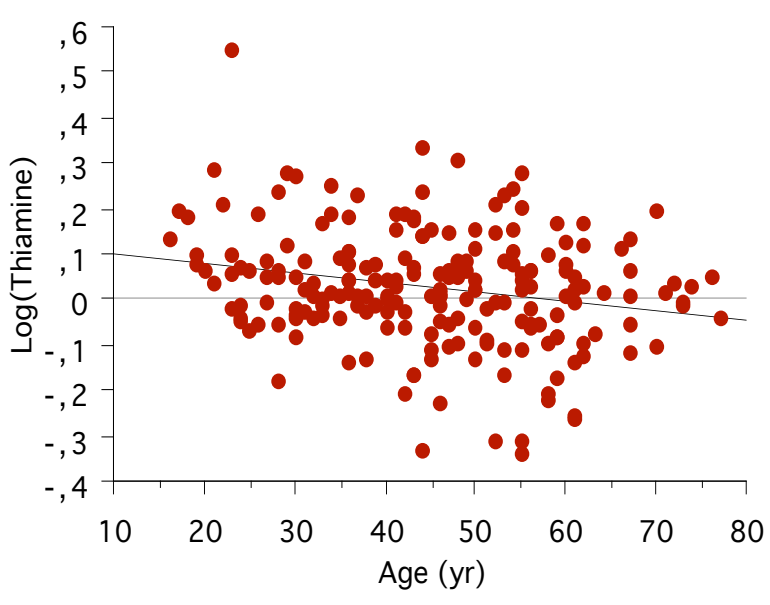

Fig. (1). Bivariate regression plot showing the negative relationship between age and estimated daily intake of vitamin B1 (thiamine).

\section{FACTORS AFFECTING MACRO AND MICRO- NUTRIENT INTAKE IN ADULTS}

In developed countries, macronutrient malnutrition usually includes excess intakes of total fat, saturated fat, and cholesterol and inadequate intake of fibre [29]. Dietary intake differences in the population can be explained by identifiable characteristics such as gender, age, racial and ethnic identity, educational attainment, and income. Educational attainment plays a crucial role as determinant of health outcomes by influencing health behaviours and choices; it raises technical and allocative efficiencies of input use. However, dietary differences among individuals are the outcomes of a complex interplay between individual, social and economic circumstances:

- nutritional requirements (related to sociodemographic and anthropometric characteristics),

- $\quad$ psychological factors (included psychosomatic and psychiatric disorders) [30],

- desires for healthful living and healthful diets,

- $\quad$ taste, preferences, and pleasure,

- $\quad$ limited resources (income at disposal, food prices and prices of other consumption goods),

- $\quad$ poor food storage and preservation,

- $\quad$ time available for cooking and food preparation, and the ability to combine foods.

Micronutrients (essential trace elements and vitamins) have a central role in metabolism and in the maintenance of tissue function [31]. Although classic vitamin deficiency syndromes are uncommon in Western societies, some clinical subgroups remain at risk (such as elderly and hospitalised patients, alcohol-dependent individuals). Moreover, subclinical inadequate intake of several vitamins is now considered more common than previously believed and has been associated with chronic diseases [6]. Micronutrient nutri- tional status is considered to be affected by a combination of increasing demand (acute infection, surgery, or trauma), reduced intake (anorexia, chronic alcohol misuse, parenteral nutrition), and/or increased losses (blood loss, diarrhoea, burn, dialysis) [31]. However, our findings in a sample of healthy and diabetic people suggests that macro and micronutrient malnutrition is common and simply related to poor dietary habits rather than to intervening precipitating circumstances. Much more has to be done on the ground of public education although decreasing purchasing power (limited income) vs food prices in mounting progression are becoming the principal restrains for Italian consumers, to a greater extent just for the specific groups at risk of malnutrition such as elderly pensioners.

\section{ABBREVIATIONS}

LTI $=$ Lowest Threshold Intake

AR $=$ Average Requirement

PRI $=$ Population Reference Intake

RDA $=$ Recommended Dietary Allowance

SCF $=$ Scientific Committee for Food

DRI $=$ Dietary References Intake

EAR = Estimated Average Requirement

$\mathrm{UL}=$ Tolerable Upper Intake Level

AMDR = Acceptable Macronutrient Distribution Ranges

DAFNE $=$ Data Food Networking

HBS $=$ Household Budget Survey

STOA $=$ Scientific and Technological Options Assessment

EPIC $=$ European Prospective Investigation of Cancer and Nutrition

\section{REFERENCES}

[1] FAO/WHO/UNU. Minimum physiological requirements and recommended dietary allowances. ESN: FAO/WHO/UNU/EPR/81/14.

[2] Scientific Committee for Food. Nutrient and energy intakes for the European Community. Commission of the European Communities, Directorate General Industry. Office for Official Publications of the European Communities, Luxembourg, 1993.

[3] Food and Nutrition Board, Institute of Medicine, National Academy of Sciences. Dietary Reference Intakes: calcium, phosphorus, magnesium, Vitamin D, and fluoride. National Academy Press, Washington DC, 1997.

[4] Scientific Committee for Food, European Commission. Tolerable upper levels of intake of vitamins and minerals, 2000. Internet: http://europa.eu.int/comm/food/fs/sc/scf/out80_en.html

[5] Taubes G. The soft science of dietary fat. Science 2001; 291: 253645.

[6] Fairfield KM, Fletcher RH. Vitamins for chronic disease prevention in adults. JAMA 2002; 287: 3116-26.

[7] Heaney RP. Long-latency deficiency disease: insights from calcium and vitamin D. Am J Clin Nutr 2003; 78: 912-9.

[8] Wright ME, Lawson KA, Weinstein SJ, et al. Higher baseline serum concentrations of vitamin $\mathrm{E}$ are associated with lower total and cause-specific mortality in the Alpha-Tocopherol, BetaCarotene Cancer Prevention Study. Am J Clin Nutr 2006; 84: 1200-7.

[9] Scientific and Technological Options Assessment (STOA). Nutrition in Europe: Nutrition policy and public health in the European Community and models for European eating habits on the threshold of the 21st Century. Luxembourg, European Parliament, Directorate General for Research, 1997. 
[10] Scientific and Technological Options Assessment (STOA). European Policy of Food Safety: Final Study. Luxembourg, European Parliament, Directorate General for Research, 2000.

[11] Matteucci E, Passerai S, Mariotti M, et al. Dietary habits and nutritional biomarkers in Italian type 1 diabetes families: evidence of unhealthy diet and combined-vitamin-deficient intakes. Eur J Clin Nutr 2005; 59: 114-122.

[12] Pala V, Sieri S, Palli D, et al. Diet in the Italian EPIC cohorts: presentation of data and methodological issues. Tumori 2003; 89: 594-607.

[13] Trichopoulou A, Naska A. DAFNE III Group. European food availability databank based on household budget surveys: the Data Food Networking initiative. Eur J Pub Health 2003; 13: 24-8.

[14] Giampietro O, Virgone E, Carneglia L, Griesi E, Calvi D, Matteucci E. Anthropometric indices of school children and familiar risk factors. Prev Med 2002; 35: 492-8.

[15] Challem JJ. Toward a new definition of essential nutrients: is it now time for a third 'vitamin' paradigm? Med Hypotheses 1999; 52: 417-22.

[16] Matteucci E, Giampietro O. Central Italy: unexpected macro- and micro-nutrient deficiencies in regular diet of residents from Pisa province. The potential role of medical education in young people. $1^{\text {st }}$ ed. Charter 7 in: Vesler LV, Ed. Malnutrition in the $21^{\text {st }}$ century. Hauppauge NY: Nova Sciente Publishers, 2007: 127-45.

[17] Streppel MT, Arends LR, van't Veer P, Grobbee DE, Geleijnse JM. Dietary fiber and blood pressure. A meta-analysis of randomized placebo-controlled trials. Arch Intern Med 2005; 165: 150-6.

[18] Kaline K, Bornstein SR, Bergmann A, Hauner H, Schwarz PE. The importance and effect of dietary fiber in diabetes prevention with particular consideration of whole grain products. Horm Metab Res 2007; 39: 687-93.

[19] Bingham SA, Day NE, Luben R, et al. Dietary fiber in food and protection against colorectal cancer in the European Prospective Investigation of Cancer and Nutrition (EPIC): an observational study. Lancet 2003; 361: 1496-501.
[20] Weickert MO, Pfeiffer AF. Metabolic effects of dietary fiber consumption and prevention of diabetes. J Nutr 2008; 138: 439-42.

[21] Salvini S, Parpinel M, Gnagnarella P, Maisonneuve P, Turrini A. Dati di composizione degli alimenti per studi epidemiologici in Italia. Milano: Ed. Istituto Europeo di Oncologia, 1998.

[22] Pettifor JM. Nutritional rickets: deficiency of vitamin D, calcium, or both? Am J Clin Nutr 2004; 80: 1725S-9S

[23] Whiting SJ, Calvo MS. Dietary recommendations to meet both endocrine and autocrine needs of Vitamin D. J Steroid Biochem Mol Biol 2005; 97: 7-12.

[24] Mataix J, Aranda P, Sánchez C, Montellano MA, Planells E, Llopis J. Assessment of thiamin (vitamin B1) and riboflavin (vitamin B2) status in an adult Mediterranean population. Br J Nutr 2003; 90: 661-6.

[25] Seccareccia F, Alberti-Fidanza A, Fidanza F, et al. Vegetable intake and long-term survival among middle-aged men in Italy. Ann Epidemiol 2003; 13: 424-30.

[26] Su LJ, Arab L. Salad and raw vegetable consumption and nutritional status in the adult US population: results from the Third National Health and Nutrition Examination Survey. J Am Diet Assoc 2006; 106: 1394-404.

[27] Strocker R. Vitamin E. Dietry supplements and health. Novartis Foundation Symposium 282: Dietary supplements and health. Wiley, Chichester, 2007: 77-92.

[28] Traber MG. How much vitamin E?...Just enough! Am J Clin Nutr 2006; 84: 959-60.

[29] Variyam JN. Factors affecting the macronutrint intake in U.S adults. Electronic report from the Economic Research Service, United States Department of Agriculture, Technical Bulletin Number 1901, 2003. Internet: http://www.ers.usda.gov

[30] Fassino S, Daga GA, Pierò A, Delsedime N. Psychological factors affecting eating disorders. Adv Psychosom Med 2007; 28: 141-68.

[31] Shenkin A. Micronutrients in health and disease. Postgrad Med J 2006; 82: 559-67. 